\title{
summary
}

\section{No need to stop low-dose aspirin therapy prior to oral surgery}

Ardekian L, Gaspar R, Peled M, Brener B, Laufer D. Does low-dose aspirin therapy complicate oral surgical procedures? JADA 2000; 131:331-335

Question: In patients who need oral surgery is it necessary to stop low-dose aspirin prior to treatment?

Objective To assess the effect of low-dose aspirin on intra- and post-operative bleeding during oral surgery.

Design Randomised controlled trial (RCT).

Intervention Thirty-nine patients requiring oral surgery were randomised either to a control group where low-dose aspirin was stopped 7 days prior to treatment or to a test group where aspirin therapy was continued.

Outcome measures Bleeding-time test, intra-operative bleeding.

Results In 33 out of the 39 patients, intra-operative bleeding was controlled with sutures and local pressure with gauze. The other six patients (see Table 1) had tranexaminc acid added to the local packing to control bleeding. No postoperative bleeding or other complications were reported at 1 week.

Conclusion The study suggests that there is no need to stop lowdose aspirin therapy for dental extractions and risk thromboembolic, cerebrovascular or myocardial complications.
Table 1 Bleeding of patients where aspirin treatment was stopped or continued

\begin{tabular}{lccc}
\hline $\begin{array}{l}\text { Treatment } \\
\text { group }\end{array}$ & $\begin{array}{c}\text { Patients } \\
(\mathrm{n})\end{array}$ & $\begin{array}{c}\text { Bleeding } \\
\text { time } \\
{[\mathrm{min}(\mathrm{SD})]^{*}}\end{array}$ & $\begin{array}{c}\text { Patients with severe } \\
\text { intra-operative } \\
\text { bleeding [n (\%)] }\end{array}$ \\
\hline $\begin{array}{l}\text { Aspirin continued } \\
\text { Aspirin stopped }\end{array}$ & 19 & $3.10( \pm 0.65)$ & $4(21.5)$ \\
\hline
\end{tabular}

*Normal range, 1-4.5 min.

Evidence-Based Dentistry (2002) 3, 66. doi:10.1038/ sj.ebd. 6400122

Address for reprints: L Ardekian, Department of Oral and Maxillofacial Surgery, Rambam Medical Centre, Haifa, Israel.

\section{Commentary}

This paper by Ardekian and colleagues reports the outcome of a RCT conducted to provide evidence to support or dispute the age-old practice by our medical colleagues of recommending stopping aspirin intake for 7-10 days before any surgery, including dental extractions. Aspirin therapy has been used routinely as a prophylaxis in the prevention of ischaemic heart disease in such patients. Aspirin is also known to cause a mild bleeding tendency by irreversibly acetylating cyclo-oxygenase, an enzyme that participates in platelet aggregation. This effect on platelet lasts for the lifetime of the platelet and can manifest for 7-10 days. ${ }^{1}$ Hence, this has formed the rationale for the stopping of aspirin as described above.
This RCT appears to be clearly focused although it is uncertain if the randomisation is concealed. It is also difficult for double-blinding in this instance. Although the number of subjects in this study is relatively small and makes this RCT look like a pilot study, nonetheless the results are valid given that the two random groups are similar, treated the same way and follow-up is complete. Although the bleeding times of both the experiment and the control groups are within the normal range, it should be noted that the bleeding time of the former is 0.7 -fold more or $1.3 \mathrm{~min}$ longer than that in the controls. Furthermore the validity of this RCT is limited to patients taking only a low dose of aspirin of $100 \mathrm{mg}$ daily.

Nevertheless the results are significant and applicable to the local population.
It is certainly clinically relevant enough for dental practitioners to apply in their management of patients with heart diseases receiving long-term low-dose aspirin therapy. The paper therefore calls into question the necessity of stopping low-dose aspirin therapy before any minor oral surgical procedures.

1. Tierney LMJ, McPhee SJ, Papadakis MA (eds) (2001). Current Medical Diagnosis and Treatment. 40th edn. McGraw-Hill: New York. p 548.

Jin Fei Yeo

Department of Oral and Maxillofacial Surgery, National University of Singapore, Singapore

Editor's note: The attract website has a short overview of this study and two similar recent papers at: http://www.attract.wales.nhs.uk/question_answers.cfm?question_id=770 